\title{
A Holistic Approach towards Personal Transformation of Youth not in Employment, Education or Training
}

\author{
Lucille Meyer \\ Rajendra Chetty
}

\begin{abstract}
This article explores how young people experienced a holistic approach to personal transformation by participating in a three month residential programme for youth not in employment, education or training. The study deployed an ecological perspective that served to illuminate the influence of relationships and contexts on the development of youth. A phenomenological approach was used to understand young peoples' perceptions and experiences of a holistic approach. The methodological framework leaned on narrative enquiry to explore the views of five youth respondents. The data was analysed using thematic content analysis. The findings illustrated that a holistic approach as one particular philosophical and developmental approach to personal transformation, has the potential to enhance the psychological capital of young people, facilitate connection with self and family and provide the impetus for them to remain on a positive developmental trajectory. As 7.5 million youth in South Africa are not in employment, education or training, a status with the propensity to foster disengagement and disconnection from self, family and social, economic, political and cultural activities, the findings offer hope that credible and innovative strategies do exist to disrupt the current NEET crisis.
\end{abstract}

Keywords: holistic approach, personal transformation, youth development, NEET. 


\section{Introduction}

This article reports on a study of a holistic approach to personal transformation for youth who are not in employment, education or training (NEET). Although the NEET label is not without controversy, as it describes youth by that which they are not (Yates \& Payne 2006:329), it nevertheless provides a useful fulcrum for focussing our attention on the status of many youth in South Africa and strategies that could be employed to disrupt this trajectory. Currently, it is estimated that 7.5 million youth are not in employment, education or training (CDE 2017:1).

The key purpose of the study was to explore youth experiences of a holistic approach to personal transformation so that we become more adept at addressing the current NEET crisis and simultaneously deepen the theory and practice of youth development. Within the current context of growing youth unemployment, the rationale for the study has grown in importance as it provides evidence-based data on the application of a holistic approach to personal transformation among youth. Over the last seven years, close to 4000 youth in the Western Cape Province (the site of the study), have participated in the programme facilitated by the Chrysalis Academy.

Disrupting the NEET trajectory is critical, as youth who are not in employment, education or training have a greater propensity of becoming disengaged and disconnected from self, family and broader structures within society (Norton et al. 2014:479). In fact they lose connection to social institutions (Vigil 1993:95). Panday et al. (2012:101) maintain that disengagement steer young people toward alternative structures to develop their sense of identity. The disconnection can become so deep, that young people are at risk of separating themselves completely from the broader society. They then carve out their identities based on risk factors such as substance abuse, peer pressure and gangs (Norton et al. 2014:479). The disengagement tends to impact negatively on the psychological capital of youth, which includes their 'hope, self-esteem, positivity and resilience' (Korthagen 2013a:14). Kessler (2000:xii) supports this view and associates 'emptiness, meaninglessness and disconnection' with a 'spiritual void' felt by young people. She maintains that although the socioeconomic issues which are the source of much violence must be addressed, there is simultaneously a need to meet the spiritual needs of young people (Kessler 2000:xii).

Although it is generally accepted that many youth experience some 
form of identity crisis as they transition into adulthood (Erikson 1968:128), this crisis is amplified in the lives of working-class youth who have to contend with heading households owing to the absence or death of parents and a socioeconomic context of poverty, lack of access to quality learning opportunities, unemployment and deepening inequality (Soudien 2007:xi). It is evident that the context within which many young people are growing up is fraught with complexity, challenges and despair as well as hope. Despite the increased investment in education following the ushering in of the democratic dispensation in 1994, the conditions under which learning is taking place in the majority of schools in poor communities have not improved significantly and inequalities continue to persist. Schools still do not have basic amenities like toilets, and suffer from poor-quality teaching, overcrowding, and extremely low levels of teacher morale and dedication (Chetty 2014:96). In Cape Town, some learners even need to join a local gang in order to pass safely through the school gates (Pinnock 2016:209). The experiences of learners in the classroom greatly influence their attitude to schooling and young people turn away from the academic and relational aspects of schooling, where there are limited qualified educators and an environment that is not conducive to learning (Fine 2002:24).

It is evident that educational achievement is greatly influenced by family socioeconomic conditions (Crouch 2005:6). The high school dropout, largely as a consequence of underlying structural policies and practices within the education system, is a huge concern for youth, their parents and the state. Of every cohort of learners that enter the schooling system, only $48 \%$ complete Grade 12 (John 2012:35). Many black working-class youth who do complete schooling may not meet the entry requirements for higher education institutions owing to poor-quality scholastic achievement. In 2014, out of 532860 learners who wrote the National Senior Certificate (Grade 12), only $28.3 \%$ qualified for entry into a bachelor's degree (DBE 2016:22). Increasingly we are witnessing that early school exits are leading not only to underemployment or unemployment but criminal behaviour (Guerra \& Bradshaw 2008:2). Hence, despite the vision of the educational reform process post 1994, there is evidence of the growth of social bifurcation through education (Motala \& Vally 2010:88).

The majority of young people who complete high school are left with little options, since the low number of seats at universities are filled by middleclass and urban-based students. Even for those who are successful at finding a 
place at university and complete a university degree programme, the chances of securing employment are limited, given the high rate of unemployment among graduates (Chetty 2014:89). The small number of black students who are able to obtain scholarships are the privileged ones with good matriculation results from advantaged schools where parents are able to afford high fees. The opportunities for poor and working-class students from dysfunctional schools, who are in far greater financial need, are limited when the key factor for funding is merit, as opposed to poverty, class and need. Despite there being constitutional and legislative imperatives to achieve a 'just, fair, equitable and humane social order with the mélange of official policy that only looks impressive at face value', the interests of the poor and marginalised are unfortunately not the premise on which the educational system post 1994 is built (Chetty 2014:89).

The study is significant in light of the growing NEET numbers and the paucity of research on credible and sustainable solutions to the NEET crises. Development pathways capable of facilitating personal transformation in youth who have become disconnected and disengaged are urgent. Especially important is the need for youth voices on their perceptions of their needs to advance their own growth. The risk profile of youth in the province is higher than that in other provinces in the country (Western Cape Government 2014:4). The province has an estimated 6.2 million people (South African Institute of Race Relations 2017:6). The youth population (15-34) is approximately 2.1 million (Stats SA 2016:8). The number of youth classified as NEET in the Western Cape is similar to the national figure (32\%), while almost $15 \%$ of school learners live in homes where someone is a member of a gang (Western Cape Government 2014:4).

\section{Context of the Study}

The study focussed on young people who participated in a three-month programme offered by the Chrysalis Academy (CA), a non-profit youth development organisation, based in the Western Cape, South Africa. The CA implements a holistic approach, aimed at deepening the resilience of youth through physical, mental, emotional and spiritual empowerment, enabling them to become positive role models and productive citizens. The programme is offered to youth who are aged 18-25; have a minimum Grade 9 and no 
criminal record. In 2006, the CA was described as a best practice example in youth crime prevention (Cooper \& Ward 2012:252).

The CA believes that despite the issues that youth may present on entering the programme, they are fundamentally whole human beings. Secondly, although they present psychosocial issues, these are fundamentally socially-induced as highlighted in the youth narratives. Examples of this include a young person who witnessed his father beating his mother and grows up believing that violence is an appropriate response in dealing with interpersonal conflict; or a young person abandoned by his mother, while his father is in prison and in a gang.

The CA uses a structured and regimented approach, supported by love and compassion to accelerate the development and growth of young people. Three cohorts are recruited per year: two male and one female course. The majority come from income-poor homes, with many being unemployed at the time of entering the programme.

The programme is conceptualised and enacted in different phases over three-months:

- A three-week orientation phase aimed at providing skills to build personal mastery and agency as well as to introduce learners to a structured and regimented environment.

- A two-week outdoor phase aimed at enhancing youth leadership capability and introducing learners to the beauty of the Western Cape and basic biodiversity issues. The outdoor phase consists of a 24-hour 'solo', which is a period of solitude to enable reflection, contemplation and connection with Self.

- A four-week skills phase aimed at providing basic technical and vocational training as a foundation for further training when exiting the CA programme or for entry-level employment in various industries or sectors. These include firefighting, welding, electrical circuitry, basic cookery, office administration and so forth.

- A two-week community phase which includes a focus on careers and professional behaviour in the workplace; cultivating citizenship and a spirit of voluntarism through community service; and a three-day route march from Tokai to Cape Point in the Western Cape as a symbol of their determination and achievement.

- A one-week exit phase focusing on financial literacy, preparing stu- 
dents to reintegrate into families and communities and how to sustain the transformation back home. Various ceremonies take place during this phase, such as a prize-giving celebration to honour student achievement and a graduation ceremony where their achievements are publicly acknowledged by family, friends and the CA.

Due to the large number of challenges experienced by youth entering the programme such as trauma, physical violence, neglect and psychological abuse, a central element of the programme is psychosocial support, which is provided through one-to-one counselling and group work. A five-year aftercare programme commences after students graduate. This includes refresher days, counselling when required, career information, and assistance to access bursaries and job opportunities. This is in recognition that transformation and selfdevelopment are incremental and ongoing, and need to be supported, especially in view of graduates' challenging home and community circumstances.

The holistic approach at the CA influences the curriculum, teaching methods and institutional culture, so that all dimensions of a human being are deliberately and consciously incorporated in the teaching and learning.

\section{Literature Review}

Beckwith (2008:28) notes that a distinction should be made between change, improvement and transformation. Personal transformation, to be sustainable, has to be a process of renewal, reconnection with self or rebirth. It is largely a process facilitated from the outside, but is fundamentally an inner process of connecting with self, discovery of one's potential and recognition of the interconnectedness between human beings and the environment. It is in the recognition of who one really is, that the transformation occurs. Change is regarded as a change in consciousness, which results in a change of behaviour (Beckwith 2008:28-29). The process of transformation includes change, but change does not incorporate transformation. Change has its limitations, whereas transformation is "limitless as it derives from an evolving discovery and expression of the Authentic Self' (Beckwith 2008:29). Personal transformation takes place when we act from our true nature (Beckwith 2008:30). Tolle (2005:21) argues that personal transformation is about the destruction of old 'mind patterns' and the development of 'new dimensions of 
consciousness', while Wade (1998:715) describes personal transformation as a form of 'rebirth', culminating in fundamental changes to how one perceives one's reality.

\section{A Holistic Approach to Personal Transformation}

The word 'holistic' refers to the 'whole', derived from the Greek word holos (OED 2009:443). Edwards (2013:531) points out that a holistic approach, predates modern times, and draws on all major spiritual and wisdom traditions, yet, its ancient foundation is marginalised. Bohm (1980:25) argued that in the initial stages of the development of civilisation, human viewpoints were that of wholeness and that in the Eastern world that view survived. He asserts that 'reality' has always been whole, but human thinking has been fragmented. Once a person is able to bring her awareness to her habit of thinking in a fragmented way, the fragmentation will end. Bohm (1980:9) avers that the fragmentation is not only in human thinking, but also in the process of thinking itself and therefore it is both the 'fragmentary process and fragmentary content' that should end together.

Similarly, Strozzi-Heckler (2014:32) affirms that the concept of an integrated mind-body process has evolved from ancient Asian and Middle Eastern cultures, philosophy and practice. It appeared in the Western world as a philosophy only in the 1930s with the work of Willhelm Reich, a student of Freud, who maintained that by working with the body through touch and breath, it was possible to cure patients. Colley (2003:81), in tracing the genealogy of holism, points to its use in the scientific field of biology in the 1920 s, contending that its use in the field of education started in the 1960s. The references to the ancient foundation of a holistic approach are important as when concepts are appropriated from the cultural practices of indigenous people, the original intention and meaning are often lost through the process of appropriation, either deliberately or mistakenly.

Ancient Vedic texts such as the Bhagavad Gita, written in the third and fourth centuries $\mathrm{BC}$, contain references to the interconnectedness and oneness or wholeness of all life forms through use of Sanskrit terms such as Tat-TwamAsi, which implies that human beings are all extensions of one universal energy (Chopra 2003:187). Hodgkinson (2006:10) speaks of the 'triple canon' of Vedanta as comprising the Upanishads, the Bhagavad Gita and the Brahma Sutras. 
According to commentaries on the Upanishads, reference is made to the notion of five sheaths: food, vital force, mind, intellect, and bliss (Hodgkinson 2006:103). Nirmalananda (2009:42), provides further insights on the five sheaths: Annamaya kosha (physical body or the food body); Pranayama kosha (energetic body or the vital force); Manomaya kosha (mental body); Vijnanamaya kosha (wisdom or intuitive body or the intellect); and Anandamaya kosha (bliss body). These sheaths are one coherent whole, and influence and impact one another. With respect to an individual, the physical implies the physical body; the energetic refers to the energy (life force) within the body. Emotions can be described as energy in motion as they come and go. The mental body refers to the mind; the intuitive body refers to the intellect; and the bliss body houses 'spirit' or 'soul'. When one reaches the anandamaya kosha, one reaches the innermost Self (Sivananda 2012:394).

The Self is already present, not something which needs to be achieved (Hodgkinson 2006:105). This may imply that personal transformation is a recognition of the 'self' within, as alluded to by Tolle (2005:23) and this recognition of the self within is the transmutation itself. The objective of our lives is to 'evolve' all of the different sheaths and in the process discover our spiritual nature (Vivekananda 2005:10). It is discovering the 'unity of the individual's consciousness with the ultimate consciousness' (Vivekananda 2005:14).

The centre of a human being is the heart, not the head, which is something that ancient civilisations were aware of, but which was forgotten by contemporary society (Keepin 2016:197). This is due to science largely not taking cognisance of 'the subjective inner dimensions of life' with its advances being recognised in the technological domain: 'Interiorization is therefore the key to spiritual practice. The path of divine love is pursued deep within the heart' (Keepin 2016:201).

Schumacher (1978:47), in support of a holistic approach, notes that many teachings describe humans as comprising four bodies: physical, etheric, astral and I/ego/self/spirit. These four levels can be compared to an 'inverted pyramid where each higher level comprises everything lower and is open to influences from everything higher' (Schumacher 1978:46). He asserts that knowledge of the four great levels of being is found in all major wisdom traditions and has been around for thousands of years.

Chopra (2003:35) posits another way of understanding a holistic approach. He outlines three levels of existence: the physical, quantum, and the 
non-local domains. The physical domain is all that which we can experience with our five senses. The quantum level is all that which cannot be seen or touched by the senses. It is the level of information and energy and includes the mind, thoughts and ego (Chopra 2003:35). Whatever exists in the quantum domain is not fixed, yet we all have experienced millions of thoughts rushing through the mind. All that which is in the physical domain can be seen to reflect that which is in the quantum domain (Chopra 2003:37).

The non-local domain is also referred to as the virtual or spiritual domain (Chopra 2003:43). It is the level of 'potentiality' and is termed 'nonlocal' as it is not confined to a particular area. It is an energy that organises what is. It is a difficult concept to grasp, but can be experienced. The notion of the non-local domain has been in contention for many years, but in the twentieth century it became possible for science to prove its existence (Chopra 2003:46).

Within the context of a discussion on personal transformation, various methods or approaches can be used to access the 'inner self' such as yoga as described by Cope (1999:324) as well as the practice of somatics. Somatics signifies the 'living, aware, bodily person' (Strozzi-Heckler 2014:31). The field of somatics, founded by Thomas Hanna, regard the body as the 'unified space in which humans act, perceive, think, feel, sense, express emotions and moods, and live in their spiritual longing' (Strozzi-Heckler 2014:33). The mind and body are not regarded as separate. The physical body is connected to the self and when the body is worked with, it leads to the question of what is beyond the self (Strozzi-Heckler 2014:38). This means that through the body, we develop the self. The somatic field makes it possible to have a view of the whole human being, as many views of the human being have often been incomplete (Hanna 1988:21).

Korthagen (2013b:35) developed the Core Reflection Approach in education and states that flow happens when people are supported to connect with their 'thinking, feeling and wanting'. He feels that if people are stuck in one dimension like the head, then flow cannot occur (Korthagen 2013b:35). Core reflection is an approach that seeks to 'nurture the whole student and teacher' and to pay attention to issues of 'identity, mission, inspiration and passion' (Greene et al. 2013:3). This approach is a strengths-based approach and is essentially about connecting human hearts and spirits.

Connecting a person's inner qualities and experiences is important, as Korthagen believes that very little attention is paid to the 'internal' and natural 
qualities that individuals bring to teaching and learning (Korthagen 2013a:14). Greene et al. (2013:4) believe that if education is oriented towards a core reflection approach then deep transformation is likely to take place. When learning becomes a joyful or meaningful experience for students, it touches the spirit in ways that cannot always be measured, but that can leave a lasting imprint on their deeper sense of being (Greene et al. 2013:5). Core reflection stems from a positive psychology approach that focuses on people's personal strengths. A deficiency model is to look at what is not going well and then to work at how to improve things, whereas a core reflection approach focuses on nurturing what is best (Korthagen 2013a:14).

Bohm notes that because many people have a 'fragmentary self-world view', they begin to perceive that this is in fact 'the way everything is' (Bohm 1980:15). In similar vein, Shepherd (2010:2) argues that the biggest harm that has been done to us by society is through the divisions imposed on us. He notes that society exhorts us to ignore the intelligence of the body and to live as 'prisoners in our craniums' (Shepherd 2010:3). The human soul has an 'age old quest for wholeness - that is to feel the world as a whole and the self as a whole within it, and in feeling that wholeness, to live it' (Shepherd 2010:6). Similarly, an individual is a spiritual entity who is engaging with the world through using the body and mind as the instrument (Vivekananda 2005:23).

Caine and Caine (1995:23) articulate the holistic approach in the following way:

Teaching Jimmy to fly a kite may involve some direct instruction, but anyone who ever experienced flying a kite on the beach will recall that they also learned about the feeling of sand under the bare feet, the smell and sound of the sea, the feel of the wind as it pulled on the string, and at the same time managed spontaneously complex mathematic calculations of distance and speed, either pursued or abandoned the sport, and possibly learned something about parents' patience and so on.

Delgado (2002:278) maintains that our concept of education must be expanded to include domains other than cognition, while Martin (1985:80) argues that emotions and feelings must be regarded as 'positive rather than untrustworthy elements of personality'. He points out that if an integrative approach is not taken, learners will not be able to feel injustices, and will have no desire to sol- 
ve real problems in the world (Martin 1985:73).

According to Campbell (2006:29), holistic education sets out to 'encompass and enlist' three key aspects of the whole person: mind, body, and spirit in the learning process and environment. This is critical as the education system fragments each discipline. Campbell (2006:29) maintains that teachers should see their students as whole developing humans with a variety of needs, including their need for personal transformation and should not suppress things like spirituality. Kessler (2000:x) argues that the 'body of the child will not grow if it is not fed, the mind will not flourish unless it is stimulated and guided and the spirit will suffer if it is not nurtured'.

In what can be seen as a support of a whole person approach, Garbarino (1999:154), who has worked with youth who have committed violent crimes, outlines what he calls a conceptual toolbox to save lost boys; this includes the spiritual dimension. He points out that of all the things he found when working with violent youth, 'a spiritual emptiness' was the most common thread. He notes that spirituality is a recognition that as human beings, we are not only 'humans with a brain', but spiritual beings as well, and that not having one's spiritual needs met can be as harmful as not having one's physical or emotional needs met.

Garbarino's perspective is shared by Kessler (2000:ix) who maintains that despite some children having their 'inner lives numbed' by drugs, neglect and abuse; many continue to come to school 'with their souls alive and seeking connection'. For Kessler the issue is how spiritual development is addressed in schools. She maintains that there is general agreement that a spiritual emptiness or a 'spiritual hunger' is what many youth face, and that these issues are largely omitted from our analysis. She defines a spiritual void as those feelings of 'emptiness, meaningless and disconnection' (Kessler 2000:xi). Delgado (2002:97) cautions that spirituality is more 'inclusive' than religion and one can be spiritual and not be religious. He argues that spirituality can be cultivated in many ways in youth development programmes and that youth practitioners should not be fearful of including it in their activities (Delgado 2002:97).

Spirituality plays an important role in 'instilling and sustaining hope' and in making meaning of a 'disadvantaged existence' (Dass-Brailsford 2005:586). Although research has shown that spirituality supports a resilient outcome, Dass-Brailsford cautions against simply accepting research outcomes that support faith in a 'higher power' as a mechanism with which to 
cope (2005:586). Caine \& Caine, (1995:25-26) aver that learning should engage the 'whole physiology' and it is important to acknowledge that learning is 'enhanced or inhibited' by threat. This perspective confirms the importance of integrating all aspects of a learner's being. A learner cannot learn if he/she is fearful or suppressing fear, and fear is not a cognitive concept, it is contained within the physical body (Van der Kolk 2014:46). Hence, learning should embrace more than the cognitive; it should engage all aspects of a learner's being, including the body that 'houses' the fear, mind and spirit. Once learners' emotions are separated from learning, they are limited from making 'meaningful connections' which are critical in enabling them to develop 'compassion, personal interdependence and tolerance for multiple perspectives' (Jennings 1995:73).

Unfortunately, many educational institutions see their mission simply as imparting knowledge, while a holistic approach integrates the learner's many selves into the learning experience (Best 2008:344). A whole person approach to education is important in that it enables the learner to integrate the power of the 'mind, heart and will' and to develop a sense of identity as part of a global family (Podger et al. 2010:342). The dominant viewpoint in our society largely proclaims that learning resides within the domain of the mind or intellect and that the body is used primarily to serve the mind.

Holistic youth development questions the view that youth are not whole right now. It is an approach to think about the ways in which youth grow, learn and evolve. There are many aspects that make up the 'world' of youth. These aspects are: the emotional, physical, familial, social, spiritual, ethical, educational, and cultural (Fletcher 2014:6). It is vital that all these aspects are included in programmes aimed at promoting youth development. It is critical for adults to regard youth as 'uniquely important people right now', instead of seeing them as 'adults-in-the making' (Fletcher 2014:7). Young people are often viewed as 'problems in the making or as current problems' (Fletcher 2014:10). Youth are capable of changing the world they live in, rather than only 'consuming' the world that they have inherited. One central tenet of a holistic youth development approach is that 'all young people have inherent value no matter how they are identified by others' (Fletcher 2014:12).

\section{Methodology}

The critical research question is: How do NEET youth experience a holistic 
approach to personal transformation? Narrative inquiry was chosen as methodological framework and the study incorporated tools that enabled youth voices to be heard. Schonert-Reichl (2000:10) points out that many researchers have expressed concern about the lack of qualitative research that illustrates young people's own interpretation of their experience, as this data has the possibility of influencing the implementation of effective programmes. Gallagher reminds us:

When we pay attention to what young people say and do not only in the classroom but in interviews, we refer to the politics of knowing and being known (2007:7).

By drawing our attention to this point, the authors seeks to give effect to the work of Spivak (1988) who points out that it is critical to listen to the voices of those who are normally seen as 'other' and hear them as 'constructors, agents and disseminators of knowledge' (Gallagher 2007:8).

Semi-structured interviews were conducted to collect data. Heath et al. (2009:79) note that as youth are often marginalised, the interview method can be a valuable 'expression of voice'. All interviews were conducted as conversations. 32 graduates of CA responded to an email inviting participation in the study and five qualitatively rich-cases were selected using purposive sampling. The emphasis was on the depth of the information being sought, as opposed to focussing on representivity and size of the sample (Bailey 1987:87). The inclusion criteria for the five youth respondents were completion of the CA programme over the last five years and they must be back in their communities for at least six months. The rationale for the six-month period was to ensure that there was a form of integration into families after the programme. Three Coloured males and two Black Africans, one male and one female were selected (racial classification was used in the study in the context of how it is used currently in South Africa to monitor affirmative action, inclusion and equity. However, many South Africans object to any form of racial classification). Parents or guardians were selected through a form of snowball sampling, in that each of the five youth respondents were asked to suggest one parent or guardian who could be interviewed.

Data was analysed using conceptual content analysis (Babbie \& Mouton 2001:493). At the first level, various concepts were highlighted in the transcriptions and then tabulated. The concepts were then clustered into 
themes, using some of the ideas that emerged in the literature review. The themes were interpreted and analysed against the research questions. The study was guided by ethical considerations such as informed consent; voluntary participation; respondents could withdraw from the interviews at any stage; and permission was sought to record the interviews. To give effect to the principle of confidentiality, each respondent was requested to provide a pseudonym to be used in the final report. However, all the youth respondents wanted their own names used, which speaks to the desire of young people to be recognised and have their voices heard and acknowledged. However, pseudonyms (Gary, Jacob, Vatiswa, Timothy and Libo) were used in keeping with the ethical requirements.

\section{Findings}

NEET youth have a greater propensity of becoming disengaged and disconnected from self, family and broader structures of society (Norton et al. 2014:479). The holistic approach as articulated by the respondents and their parents/guardians has a number of benefits for NEET youth. The stories that emerged from the data illustrated that their needs were many and varied, and straddled a number of dimensions including food and safety, the need to be challenged, recognised and acknowledged, and a deep longing for connection and positive role models. Vatiswa described a broad spectrum of needs that youth have which a holistic approach, due to its philosophy, design, curriculum and peer model of instruction is capable of fulfilling such as the need for a father figure; someone to talk to; peer support, nourishment in the form of food; facilitating the resolution of emotional issues, helping to build confidence and self-esteem.

Other descriptions of the multi-facetted nature of the holistic approach include how it results in 'optimal development' and build on an 'individual's strengths and improves weaknesses'. The variety of needs illustrate the notion that youth 'are never just one thing' and provide some measure of caution about programmes that may be seen as one-dimensional or too utilitarian, such as skills or work-readiness programmes, as opposed to one that is aimed at developing and nurturing the 'whole' person.

The perspectives of the youth respondents suggest that the holistic approach is transformative as it embraces all aspects of who they are and fulfils many of their individual and collective needs. Their insights give credence to 
the perspective shared by Jennings (1995:73) that if learning experiences are to be impactful, they should engage all aspects of a learner's being; in other words, they should engage all dimensions. Once a learner's emotions are separated from learning, they are not able to make 'meaningful connections' which are very important to enable them to develop 'compassion, personal interdependence and tolerance for multiple perspectives' (Jennings 1995:73). Korthagen (2013b:35) articulates this perspective slightly differently as he maintains that when people are supported to connect with their 'thinking, feeling and wanting', 'flow' happens.

A number of themes connect the dots between NEET youth and the value of a holistic approach, the key being Socioeconomic context and ecology. The narratives show how they continue to live in communities where unemployment is high and increasing, poverty is pervasive, crime is rampant, and substance abuse is a problem. All five youth described the impact of positive fathering, making the need for connection a high priority. They described issues of physical safety, fear, lack of opportunity, the 'passive' nature of their education, and lack of purpose. Their family backgrounds illustrate the deficits in economic, social, and cultural capital confronting many black youth from working-class families.

The second theme, Relationships and the need for connection, is significant as the respondents noted the absence of connection or relationship with a father figure. This may explain why they emphasised the relational value of the programme, such as being provided with a 'father figure' or 'peer support', or 'getting attention even if one is not sick'. Other themes that emerged include issues around identity, personal resilience, readiness for change and CA approach to adult learning.

An interesting element brought to the fore is the experiential nature of a holistic approach. Everything that is taught is experienced. They pointed out that the programme not only provided them with information, but it taught through 'experience' and it is precisely these 'experiences that culminated in changes to the different dimensions of their being.

The findings tell a 'political story' of the lives of young people, lives characterised by poverty, inequality, absent fathers and unemployment. Gary sums it up when he notes that 'the community is riddled with crime, gangsterism and poverty'. The narratives illustrate that many of their personal psychosocial challenges were socially induced such as an absent father, witnessing domestic violence, social marginalisation and exclusion as well as poverty. 
However the findings simultaneously conveyed a deep desire for change, achievement and a striving for excellence. The stories reveal how poverty and trauma is intergenerational. Their stories before their tenure at the academy were in fact the stories of their parents. Jacob, points out that:

Over the years, I have come to understand, that my fear was almost like a genetic-trait. I think it was a fear from my parents. I think that whatever my parents feared was almost like transferred to me.

The respondents reported many changes on a number of different levels: physical, mental, emotional and spiritual. The most significant changes were perceived to be in the mental, emotional or energetic and spiritual domains. Changes included:

- $\quad$ Physical changes: Weight loss; becoming fitter; putting on weight (this is a necessity where someone has lost weight due to drug use); became healthier.

- Mental changes: Perception of things changed; developed a realisation that human beings and nature are connected; developed a greater sense of purpose; developed the ability to think more deeply about identity questions; mental frame changed, although physical circumstances did not; realised that I am a leader.

- Emotional changes: Able to connect with emotions; speak about emotions; more aware of what is going on around myself; manage emotions; more self-confident; ability to communicate better; less reactive; released many emotions; more calmer; more accepting of myself; more open on an interpersonal level; gained self-respect; gained self-trust.

- Spiritual changes: Grew stronger spiritually; faith started growing; became more aware of who I am spiritually.

Timothy captures his transformation poignantly:

I underwent many changes during the three months. Firstly, I became more self-accepting of myself. The three months were like a booster. I became more aware of my identity in terms of who I was. Much of my transformation was around issues of self-identity. I also became more aware of who I was on a spiritual level. There were not many physical changes, but there was an inner change that I could identify with. 


\section{Lucille Meyer \& Rajendra Chetty}

On the value of a holistic approach, the respondents felt it was able to meet a range of needs that young people have: from food, safety, new ideas, role models and spiritual needs. The data shows that the needs of youth are indeed varied and straddled a number of dimensions, and that a holistic approach with its multidimensional nature, excluded none of their needs. They showed immense appreciation that none of who they were and what they brought to the programme was excluded. Jacob noted:

I think that the Chrysalis Academy runs a holistic programme as they develop all aspects of a human being, which means there is optimum development. The CA makes provision for all systems in your life.

They also felt that a holistic approach was powerful due to its experiential nature. In other words, everything that was taught was experienced. What was taught was not only cerebral, but was 'in the body, mind and spirit' of the respondents. This confirms the view that despite the many critics, 'there is growing consensus that experience forms the basis of all learning' (Kolb 1984:3 $4)$.

The biggest contributor to their change was time spent in nature over the two-week period and more specifically in silence. In fact, it was quite paradoxical, that it was the silence experienced in nature that enabled them 'to break' their silence on issues of emotional and physical abuse. Their experiences in silence seem to suggest that the personal transformation process for some may include a process of 'walking through the fire', that is, an inner wrestling or grappling with a challenge by oneself such as the absence of a father or domestic violence. This inner wrestling seems to have the potential to commence the personal transformation process, if the individual is supported so that the process does not become too overwhelming. Vatiswa remarks that:

The solo was very difficult for me. The dad issue was the big one that surfaced during my solo. There was quite a lot of forgiving of my mom and myself. Total healing for me was about releasing that which I have parked for a long time.

Their sojourn made it possible for them to speak about their psychosocial challenges for the very first time in their lives, begging the question: What happens to youth who have no platform to speak about their personal inner challenges. It was very significant how powerful nature, being alone and 
silence were in assisting youth to deal with their issues. The findings confirmed that there is power in silence to surface psychosocial issues that might have been parked.

The findings illustrate that a personal transformation process is both an inner and an outer process, with some respondents maintaining that aspects of the transformation cannot be described in words; in other words the experiences transcend words, perhaps pointing to why it is difficult to reach consensus on the exact nature of the personal transformation process.

It was quite extraordinary, from an academic research perspective, that the youth did not wish for their identities to be hidden, conveying the desire that young people have of wanting to be seen and heard. Within an environment of safety, where participants were insulated from risks such as crime, poverty and peer pressure, they were able to 'name' issues like absent fathers, domestic violence, rape and questions around gender identity. This naming of their reality is significant, as it suggests that the process of naming diminishes the power that the issue has over their lives.

Despite the stereotypes that exist in society and research findings on the gender differences in emotional expressions (Levant et al. 2009), a holistic approach had no gender bias, in that both male and female respondents described their experiences, without reservation. There were no 'emotional restrictiveness' on the part of male respondents during the programme, and they were able to speak about issues that they had 'parked' for a long time (Levant et al. 2009:190).

There is evidence of the sustainability of the personal transformation experienced by the youth as they were either in meaningful occupation or studying at higher education institutions: this was further illustrated by their positive psychosocial disposition at the time of the interviews. All of them were still on a continuous developmental trajectory, despite one of them being unemployed.

\section{Conclusion}

The findings point to the value of a holistic approach in fostering personal transformation among youth who are not in employment, education or training. The holistic approach is not only psychological; it meets the physical, emotional, mental and spiritual needs of young people. In addition, it incorporates not only a three-month residential period, but a one-year 
internship after graduation augmented with an aftercare support service. In other words, the holistic approach, besides its focus on all dimension of a human being, provides a continuum of care. It extends beyond skills development and is about education in a broader sense. Among others, it enabled youth to become more positive; more able to connect with their emotions; develop a greater sense of purpose; give up habits such as the use of illegal substances; become fitter; develop greater self-respect and self-trust. In addition, they gained a repertoire of skills that could be used when they are confronted with difficulties after their graduation.

Youth experienced significant changes in the realm of the mental, emotional and the spiritual. The changes helped them to transform their mindset and perspectives and assisted them to manage their emotions and deal with some of their inner issues that had been pushed into the subconscious (parked). It helped to build their confidence and self-esteem which enabled them to foster better interpersonal relationships when they left the academy. Their faith and spirituality had also grown. There were significant changes in their connection with an adult figure in their lives.

The potential of the holistic approach is not only to cultivate the psychological capital of youth and to stimulate change at different levels, but to meet a wide array of critical needs that youth have as a result of their NEET status such as the need for positive role models and the need for safe spaces to speak about deep wounds accumulated over a period of time. The approach could be considered as a strategy to 'disrupt' what can be seen as a negative developmental trajectory, particularly where youth are labelled as 'disruptive'. Within the context of the growing NEET numbers, we, like the work with youth in the USA by Weiss and Fine (2001:497), maintain that the holistic approach to personal transformation is an example of a 'disruptive pedagogy' capable of positively influencing the consciousness of young people.

\section{References}

Beckwith, M.B. 2008. Spiritual Liberation: Fulfilling your Soul's Potential. New York, NY: Atria Books.

Best, R. 2008. Education, Support and the Development of the Whole Person.

British Journal of Guidance \& Counselling 36,4,November:343-351. https://doi.org/10.1080/03069880802364460 
Bohm, D. 1980. Wholeness and the Implicate Order. London: Routledge \& Kegan Paul.

Caine, R.N. \& G. Caine 1995. The Use of Brain Research as a Basis for Evaluating Integrative Approaches to Education. In Blair, B.G. \& R.N. Caine (eds.): Integrative Learning as the Pathway to Teaching Holism, Complexity, and Interconnectedness. Lewiston, NY: Edwin Mellen Press. Campbell, L.H. 2006. Spirituality and Holistic Art Education. Visual Arts Research 32,1:29 - 34.

Centre for Development and Enterprise 2017. No Country for Young People: The Crisis of Youth Unemployment and What to Do about It. Johannesburg: Centre for Development and Enterprise.

Chetty, R. 2014. Class Dismissed? Youth Resistance and the Politics of Race and Class in South African Education. Critical Arts: South - North Cultural and Media Studies 28,1:88 - 102.

https://doi.org/10.1080/02560046.2014.883692

Chopra, D. 2003. Synchrodestiny: Harnessing the Infinite Power of Coincidence to Create Miracles. London: Harmony.

Colley, H. 2003. Engagement Mentoring for Socially Excluded Youth: Problematising an 'Holistic' Approach to Creating Employability through the Transformation of Habitus. British Journal of Guidance \& Counselling 31,1:77 - 99.

https://doi.org/10.1080/0306988031000086189

Cooper, A. \& C.L. Ward 2012. Intervening with Youths in Gangs. In Ward, C.L., A. van der Merwe \& A. Dawes (eds.): Youth Violence: Sources and Solutions in South Africa. Claremont: UCT Press.

Cope, S. 1999. Yoga and the Quest for the True Self. New York: Bantam Books.

Crouch, L. 2005. South Africa Equity and Quality Reforms: Possible Lessons. Journal of Education for International Development 1,1.

http://www.equip123.net/JEID/articles/1/1-2.pdf

(Accessed on 21 June 2017.)

Dass-Brailsford, P. 2005. Exploring Resiliency: Academic Achievement among Disadvantaged Black Youth in South Africa. South African Journal of Psychology 35,3:574 - 591.

https://doi.org/10.1177/008124630503500311

Delgado, M. 2002. New Frontiers for Youth Development in the Twenty-first Century: Revitalizing \& Broadening Youth Development. New York: 
Columbia University Press.

Department of Basic Education 2016. National Education Infrastructure Management System. Pretoria: Government Printers.

Edwards, S.D. 2013. Holistic Psychology: A Brief Primer. Journal of Psychology in Africa 23,3:531 - 537.

https://doi.org/10.1080/14330237.2013.10820664

Erikson, E. 1968. Identity, Youth and Crisis. New York: WW Norton.

Fine, M. 2002. Expert Report of Michelle Fine: Decent Schools in California.

http://decentschools.org/expert_reports/fine_report.pdf (Accessed on 23

September 2017.)

Fletcher, A. 2014. A Short Guide to Holistic Youth Development. Olympia, WA: Freechild Project.

Gallagher, K. 2007. The Theatre of the Urban: Youth and Schooling in Dangerous Times. Toronto: University of Toronto Press.

https://doi.org/10.3138/9781442683891

Garbarino, J. 1999. Lost Boys: Why our Sons Turn Violent and How we can Save them. New York: Anchor Books.

Greene, W.L., Y.M. Kim \& F.A.J. Korthagen 2013. Transforming Education from Within. In Korthagen, F.A.J., Y.M. Kim \& W.L. Greene (eds.):

Teaching and Learning from Within: A Core Reflection Approach to Quality and Inspiration in Education. New York: Routledge.

Guerra, N.G. \& C.P. Bradshaw 2008. Linking the Prevention of Problem Behaviors and Positive Youth Development: Core Competencies for Positive Youth Development and Risk Prevention. New Directions for Child and Adolescent Development 122, Winter:1 - 17.

https://doi.org/10.1002/cd.225

Hanna, T. 1988. Somatics: Reawakening the Mind's Control of Movement, Flexibility, and Health. Cambridge, MA: Da Capo Press.

Heath, S., R. Brooks, E. Cleaver \& E. Ireland 2009. Researching Young People's Lives. London: Sage.

https://doi.org/10.4135/9781446249420

Hodgkinson, B. 2006. The Essence of Vedanta. London: Arcturus.

Jennings, T. 1995. Integrated Education for Human Rights. In Blair, B.G. \& R.N. Caine (eds.): Integrative Learning is the Pathway to Teaching Holism, Complexity, and Interconnectedness. Lewiston, NY: Edwin Mellen. John, V. 2012. Matric Pass Rate May be Deceiving. Mail and Guardian January, p. 10. 
Keepin, W. 2016. Belonging to God: Spirituality, Science \& a Universal Path of Divine Love. Woodstock, VT: Skylight Paths Publishing.

Kessler, R. 2000. The Soul of Education: Helping Students Find Connection, Compassion, and Character at School. Alexandria, VA: Association for Supervision and Curriculum Development.

Kolb, D.A. 1984. Experiential Learning: Experience as the Source of Learning and Development. Englewood Cliffs, NJ: Prentice Hall.

Korthagen, F.A.J. 2013a. A Focus on the Human Potential. In Korthagen, F.A.J., Y.M. Kim \& W.L. Greene (eds.): Teaching and Learning from Within: A Core Reflection Approach to Quality and Inspiration in Education. New York: Routledge: 13-23.

Korthagen, F.A.J. 2013b. The Core Reflection Approach. In Korthagen, F.A.J., Y.M. Kim \& W.L. Greene (eds.): Teaching and Learning from Within: A Core Reflection Approach to Quality and Inspiration in Education. New York, NY: Routledge.

Levant, F.R., R.J. Hall, C.M. Williams \& N.T. Hasan 2009. Gender Differences in Alexithymia. Psychology of Men \& Masculinity 10,3:190 -203. https://doi.org/10.1037/a0015652

Martin, J. 1985. Becoming Educated: A Journey of Alienation or Integration. Journal of Education 167,3:71 - 84. https://doi.org/10.1177/002205748516700305

Motala, E. \& S. Vally 2010. Class, 'Race' and State in Post-apartheid Education. In Kelsh, D., D. Hill \& S.L. Macrine (eds.): Class in Education: Knowledge, Pedagogy, Subjectivity. New York: Routledge.

Nirmalananda, S. 2009. Yogic Management of Cancer. Bihar: Yoga Publications Trust.

Norton, C.L., B.L. Wisner, M. Krugh \& A. Penn 2014. Helping Youth Transition into an Alternative Residential Youth Setting: Exploring the Effects of a Wilderness Orientation Program on Youth Purpose and Identity Complexity. Child \& Adolescent Social Work Journal 31,5:475 -493. https://doi.org/10.1007/s10560-014-0331-y

Oxford Paperback Dictionary and Thesaurus. $3^{\text {rd }}$ Ediiton 2009. Oxford: Oxford University Press.

Panday, S., C. Ranchod, B. Ngcaweni \& S. Seedat 2012. The Situation of the Youth in South Africa. In Ward, C.L., A. van der Merwe \& A. Dawes (eds.): Youth Violence: Sources and Solutions in South Africa. Claremont: UCT Press. 
Pinnock, D. 2016. Gang Town. Cape Town: Tafelberg.

Podger, D.M., E. Mustakova-Possardt \& A. Reid 2010. A Whole-person Approach to Educating for Sustainability. International Journal of Sustainability in Higher Education 11,4:339 - 352.

https://doi.org/10.1108/14676371011077568

Schonert-Reichl, K.A. 2000. Children and Youth at Risk: Some Conceptual Considerations. Paper prepared for the Pan-Canadian Education Research Agenda Symposium: Children and Youth at Risk, 6 - 7 April, Ottawa, Canada.

Schumacher, E.F. 1978. A Guide for the Perplexed. New York, NY: Harper \& Row.

Shepherd, P. 2010. New Self, New World: Recovering our Senses in the Twenty-first Century. Berkeley, CA: North Atlantic Books.

Sivananda, 2012. The Principal Upanishads. $6^{\text {th }}$ Edition. Shivanandanagar:

Divine Life Society.

Soudien, C. 2007. Youth Identity in Contemporary South Africa: Race, Culture and Schooling. Claremont: New Africa Books.

South African Institute of Race Relations 2017. South Africa Survey 2017. Johannesburg: South African Institute of Race Relations.

South Africa. Statistics South Africa. 2016. Vulnerable Groups Series 1: The Social Profile of Youth, 2009-2014. Pretoria: Stats SA.

Spivak, G. 1988. Can the subaltern speak? In Nelson, C. \& L. Grossberg (eds.): Marxism and the Interpretation of Culture. Urbana, IL: University of Illinois Press.

https://doi.org/10.1007/978-1-349-19059-1_20

Strozzi-Heckler, R. 2014. The Art of Somatic Coaching: Embodying Skillful Action, Wisdom, and Compassion. Berkeley, CA: North Atlantic Books. Tolle, E. 2005. A New Earth: Awakening to your Life's Purpose. London: Penguin.

Van der Kolk, B.A. 2014. The Body Keeps the Score: Brain, Mind and Body in the Healing of Trauma. New York, NY: Viking.

Vigil, J.D. 1993. Gangs, Social Control, and Ethnicity: Ways to Redirect. In Heath, S.B \& M.W. McLaughlin (eds.): Identity \& Inner-city Youth: Beyond Ethnicity and Gender. New York: Teachers College Press. Vivekananda, R. 2005. Practical Yoga Psychology. Munger: Yoga Publications Trust.

Wade, G. 1998. A Concept Analysis of Personal Transformation. Journal of 
Personal Transformation of Youth not in Employment, Education or Training

Advanced Nursing 28, 4:713 - 719.

https://doi.org/10.1046/j.1365-2648.1998.00729.x

Weis, L. \& M. Fine 2001. Extraordinary Conversations in Public Schools. International Journal of Qualitative Studies in Education 14,4:497 - 523. https://doi.org/10.1080/09518390110046355

Western Cape Government 2014. Western Cape Youth Development Strategy - 2013. Cape Town: Western Cape Government.

Yates, S. \& M. Payne 2006. Not so NEET? A Critique of the Use of 'NEET' in Setting Targets for Interventions with Young People. Journal of Youth Studies 9,3:329 - 344.

https://doi.org/10.1080/13676260600805671

Lucille Meyer

Postdoctoral Fellow

University of the Western Cape $\underline{\text { 3880854@myuwc.ac.za }}$

Rajendra Chetty Faculty of Education University of the Western Cape rchetty@uwc.ac.za 